\section{REVISTA DE GESTAOOE SECREETARADO}

MANAGEMENT AND ADMINISTRATIVE

PROFESSIONAL REVIEW
Organização: SINSESP

Editora Científica: Dra. Cibele B. Martins Avaliação: Double Blind Review pelo SEER/OJS Revisão: Gramatical, normativa e de formatação

Data de recebimento do artigo: 20-10-2017

Data de aceite do artigo: $9-3-2018$

DOI: http://dx.doi.org/10.7769/gesec.v9i1.732

\title{
Produção científica do Grupo de Pesquisa em Secretariado Executivo Bilíngue rumo ao stricto sensu: mutatis mutandis
}

\section{Carla Maria Schmidt}

Doutora em Administração pela FEA/USP e Mestra em Administração pela FURB. Professora efetiva da Universidade Estadual do Oeste do Paraná (Unioeste). E-mail: carlamariaschmidt@ hotmail.com (Brasil).

\section{Keila Raquel Wenningkamp}

Doutoranda e Mestra em Desenvolvimento Regional e Agronegócio (PGDRA/Unioeste). Professora colaboradora do Curso de Secretariado Executivo da Unioeste. E-mail: sebkeila@ hotmail.com (Brasil).

\section{Ivanete Daga Cielo}

Doutora em Desenvolvimento Regional e Agronegócio pela Unioeste e Mestra em Engenharia de Produção pela UFSC. Professora adjunta da Unioeste. E-mail: ivacielo@ bol.com.br (Brasil).

\section{Fernanda Cristina Sanches}

Doutoranda em Educação na Universidade Estadual de Maringá (UEM), Mestra em Ciências Ambientais pela Unioeste. Professora colaboradora do curso de Secretariado Executivo da Unioeste. E-mail: fernandacsanches@gmail.com (Brasil).

\section{RESUMO}

O Grupo de Pesquisa em Secretariado Executivo Bilíngue - GPSEB, da Unioeste, busca contribuir com a área secretarial, desenvolvendo uma proposta de programa stricto sensu. Para tanto, é fundamental que haja estreita relação entre as produções científicas dos membros pesquisadores e as linhas de pesquisa do grupo. Assim, este estudo tem como objetivo analisar a compatibilidade existente entre as produções científicas dos pesquisadores do GPSEB e as linhas de pesquisa do grupo no quadriênio (2013-2016). Este estudo é importante para o referido grupo, dada a possibilidade de ajustes e realinhamentos nas produções desenvolvidas. Para alcançar o objetivo, o referencial teórico discorre sobre o cenário da produção científica secretarial no Brasil e ainda sobre aspectos fundamentais para a abertura de programas stricto sensu, a partir da análise da Capes. Em termos metodológicos, realizou-se uma pesquisa de abordagens qualitativa e quantitativa, sendo um estudo de caráter estatístico-descritivo. $\mathrm{O}$ objeto de análise contemplou as produções científicas dos pesquisadores do GPSEB no período de 20132016, a partir de busca nos currículos Lattes dos pesquisadores. Os principais resultados apontam que os pesquisadores apresentam possibilidades para ofertar um programa de mestrado, contudo, aspectos importantes necessitam ser realinhados. Dentre eles, especial atenção deve ser dada a uma maior quantidade de publicações em periódicos e também na área específica de Secretariado.

PALAVRAS-CHAVE: Secretariado executivo. Grupo de pesquisa. Linhas de pesquisa. 


\title{
Scientific production of the Bilingual Executive Secretariat Research Group towards the stricto sensu: mutatis mutandis
}

\begin{abstract}
The Bilingual Executive Secretariat Research Group (GPSEB) from Unioeste University seeks to contribute to the secretarial area, by developing a stricto sensu program proposal. Therefore, it is essential that there is a close relationship between the research members' scientific production and the group research lines. Thus, this study aims at analyzing the compatibility between the research members' scientific production and the GPSEB research lines in the quadrennial period 2013-2016. This study is important for this group, given the possibility of adjustments and realignments in the production developed. In order to reach the objective, the theoretical framework deals with the secretariat scientific production scenario in Brazil and also with fundamental aspects for the opening of stricto sensu programs, based on Capes analysis. In methodological terms, a qualitative and quantitative approach with a statistic-descriptive research was carried out. The object of analysis was the scientific production of GPSEB researchers in the period of 2013-2016, using data extracted from the researchers' Lattes curricula. The main results indicate that the researchers present possibilities to offer a master's program. However, important aspects need to be realigned. Among them, special attention should be given to a greater number of publications in journals and also in the Secretariat specific area.
\end{abstract}

KEYWORDS: Executive Secretariat. Research group. Research lines.

\section{Como referenciar em APA:}

Schmidt, C. M., Wenningkamp, K. R., Cielo, I. D. \& Sanches, F. C. (2018). Produção científica do Grupo de Pesquisa em Secretariado Executivo Bilíngue rumo ao stricto sensu: mutatis mutandis. R.G.Secr.,GESEC, 9(1). doi: http://dx.doi.org/10.7769/gesec.v9i1.732

\section{Como referenciar em ABNT:}

SCHMIDT, C. M.; WENNINGKAMP, K. R.; CIELO, I. D.; SANCHES, F. C. Produção científica do Grupo de Pesquisa em Secretariado Executivo Bilíngue rumo ao stricto sensu: mutatis mutandis. R.G.Secr.,GESEC, v. 9, n. 1, 2018. doi: http://dx.doi.org/10.7769/gesec.v9i1.732
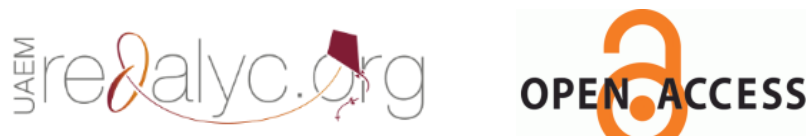

R.G. Secr., GESEC, São Paulo, v. 9, n. 1, p 18-41, jan./abr. 2018. 


\section{Introdução}

A evolução de uma profissão ou de uma área de conhecimento possui estreita relação com o seu desenvolvimento científico. Isto, porque, de acordo com Durante (2012), uma profissão é potencializada pela pesquisa, a partir da compreensão e questionamentos da sua realidade e das suas implicações na sociedade. Bíscoli e Bilert (2013) também corroboram afirmando que a pesquisa contribui para a evolução de uma área, pois por meio dela é possível desvendar a profissão e o que a cerca, como as possibilidades de atuação, as dificuldades e as alternativas do cotidiano profissional. Inclusive, para Cantarotti (2016), o pensamento crítico e a reflexão sobre a formação e tudo o que a envolve é parte constituinte dessa formação.

Nesse sentido, os pesquisadores da área de Secretariado no Brasil têm se preocupado, nos últimos anos, com o processo de delimitação, acúmulo e consolidação do conhecimento científico no campo, ou seja, com a evolução da cientificidade do Secretariado Executivo. Essa área, que inicialmente se preocupou com as questões mais técnicas da profissão, neste momento, sente a necessidade e busca se consolidar em termos científicos (Neiva \& D'Elia, 2014). Assim, principalmente desde 2010, observam-se significativos avanços no percurso da pesquisa secretarial, entre eles: melhoria na titulação dos docentes e pesquisadores, incremento quantitativo e qualitativo da produção científica, aumento do número de grupos de pesquisa e oficialização de uma associação brasileira de pesquisa (Bíscoli, 2012; Durante, 2012; Piccoli, Gonçalves, Soares, \& Martins, 2016; Pontes \& Durante, 2016).

Sabe-se também que, apesar dos avanços, há ainda diversas lacunas a serem preenchidas, dentre elas a criação de programas de pós-graduação stricto sensu voltados para a formação do profissional de Secretariado Executivo. Diversos docentes e pesquisadores da área, em recentes discussões em torno do fortalecimento do Secretariado Executivo no país, têm apontado a necessidade e urgência da criação de programas stricto sensu (Bíscoli, 2012; Durante, 2012; Schmidt, Cielo \& Sanches, 2012; Piccoli et al., 2016; Pontes \& Durante, 2016). Esses programas seriam essenciais para amenizar a lacuna relativa à formação dos egressos e, ainda, dos docentes que atuam nos cursos de Secretariado Executivo do Brasil. A área em questão necessita de docentes com formação continuada em sua própria formação de graduação. Isso é entendido como essencial e urgente para a consolidação da área, conforme

R.G. Secr., GESEC, São Paulo, v. 9, n. 1, p 18-41, jan./abr. 2018. 
afirmam diferentes pesquisadores no país (Andrade \& Soares, 2016; Brito \& Barros, 2016). Assim, entende-se como fundamental essa formação stricto sensu para auxiliar o Secretariado em sua trajetória de "se fazer e se estabelecer como ciência".

É dentro dessa perspectiva que o Colegiado de Secretariado Executivo da Universidade Estadual do Oeste do Paraná - Unioeste (alicerçado nas discussões iniciadas no Grupo de Pesquisa em Secretariado Executivo Bilíngue - GPSEB) - busca contribuir, a partir da construção de uma proposta de programa stricto sensu na área. O GPSEB, primeiro grupo de pesquisa em Secretariado Executivo certificado pelo Conselho Nacional de Desenvolvimento Científico e Tecnológico - CNPq, desde 2002, desenvolve estudos referentes a variáveis e indicadores relativos ao Secretariado Executivo Bilíngue, sendo que as atividades desenvolvidas pelo grupo têm como finalidade estimular as linhas de pesquisas dos docentes do referido curso e promover a capacitação dos acadêmicos na investigação de questões relativas à área secretarial. Ressalta-se que o GPSEB tem fundamental importância na idealização e formatação da proposta do programa stricto sensu, uma vez que o grupo realiza contínuas discussões em torno da temática e da consolidação das linhas de pesquisa dos docentes.

Contudo, no contexto de proposição de abertura de um programa stricto sensu surgiu uma lacuna a ser mais bem compreendida. Para a Coordenação de Aperfeiçoamento de Pessoal de Nível Superior - Capes (agência nacional de desenvolvimento do sistema de pósgraduação no Brasil), um dos quesitos de avaliação é o ajuste entre as linhas de pesquisa propostas e a produção científica dos docentes. Ou seja, um dos elementos a serem observados pela Capes no momento da avaliação de uma nova proposta de programa (mestrado ou doutorado) é a compatibilidade do corpo docente em relação às linhas de pesquisa (Capes, 2016). Isto porque, “a produção docente é um critério para avaliar o alinhamento entre o perfil do corpo docente e a proposta" e "a produção intelectual deve guardar estreita relação com a proposta e as linhas de pesquisa" (Capes, 2016, p. 6).

Dessa forma, este estudo possui a seguinte questão norteadora: os pesquisadores do GPSEB têm alinhado suas produções dentro do escopo das linhas de pesquisa do referido grupo? Isso se torna relevante, pois tal alinhamento será considerado no momento de submissão de proposta para programa stricto sensu. Assim, este estudo tem como objetivo analisar a compatibilidade existente entre as produções científicas dos membros pesquisadores e as linhas de pesquisa do GPSEB no quadriênio (2013-2016). Salienta-se que 
no período em análise o GPSEB apresentou as seguintes linhas de pesquisa: Assessoria e Gestão Organizacional; Empreendedorismo, Inovação e Internacionalização; Gestão Socioambiental nas organizações e Língua Estrangeira Moderna (CNPq, 2017), de forma que se busca então analisar até que ponto essas linhas de estudo foram objeto de exploração e estudo dos pesquisadores do GPSEB.

Este estudo torna-se importante para o referido grupo, dada a possibilidade de ajustes e realinhamentos nas produções desenvolvidas, considerando a proposição de um futuro stricto sensu. O título do estudo remete ao seguinte pensamento: há necessidade de mudanças na produção científica do Secretariado Executivo rumo a formação stricto sensu? A expressão latina utilizada "mutatis mutandis", que significa "mudando o que precisa ser mudado", conduz a reflexão de que para alcançar a formação de mestrado, ainda inexistente no país, possivelmente algumas barreiras precisam ser quebradas, bem como algumas mudanças e adequações necessitem ser realizadas.

Apesar de se tratar de um estudo sobre o GPSEB, as considerações e análises aqui realizadas podem contribuir também para outros cursos, pesquisadores e grupos de pesquisa, tendo em vista a conclusão consensual de vários pesquisadores, a exemplo de Oliveira e Durante (2016) e Piccoli et al. (2016), sobre a necessidade de programas stricto sensu em Secretariado Executivo no Brasil.

Para atingir o objetivo proposto, o presente estudo está estruturado em cinco partes centrais. Além desta introdução, na segunda parte são apresentadas considerações acerca da pesquisa no Secretariado Executivo e de elementos de Avaliação da Capes para criação de programas stricto sensu. Na terceira parte é explicitada a metodologia aqui adotada. A quarta parte apresenta os principais resultados encontrados. As conclusões e as sugestões para pesquisas futuras compõem a quinta parte. Por fim, as referências encerram este estudo.

\section{Referencial Teórico}

\subsection{Pesquisa em Secretariado Executivo}

A pesquisa em Secretariado vem demonstrando significativos avanços, motivados por diversos fatores que vêm delineando a história da construção do conhecimento na área. Dentre 
eles, destacam-se: disseminação de pesquisas e discussões em eventos de caráter regional e nacional; publicações em periódicos de acesso livre ranqueados pela Capes; criação da Associação Brasileira de Pesquisa em Secretariado (ABPSEC); publicação de livros, que tecem considerações acerca da pesquisa em secretariado; capacitação dos docentes em cursos de pós-graduação stricto sensu; envolvimento dos discentes no desenvolvimento de estudos relativos ao secretariado; surgimento e fortalecimento dos grupos de pesquisa; redes de produção coletiva entre pesquisadores; dentre outros.

Ademais, Martins e Zanon (2013) afirmam que um grande motivador da pesquisa ocorreu quando, em 2008, o Instituto Nacional de Estudos e Pesquisas Educacionais Anísio Teixeira (Inep) abriu chamada pública para consultar a sociedade acerca da continuidade da formação superior em Secretariado, tendo em vista a escassez de produções científicas nesse campo. A partir desse momento, docentes e pesquisadores assumiram o compromisso de divulgar seus estudos publicamente.

Nesse aspecto, é primordial o fomento da pesquisa no ensino superior, visto que nesse espaço acontece a formação dos futuros profissionais. Cabe mencionar ainda que as instituições de ensino superior se constituem em porta-vozes da pesquisa, visto que disseminam as contribuições dos pesquisadores para a sociedade e à ciência (Sanches; Schmidt \& Dias, 2017)

De acordo com Müller e Sanches (2013, p. 19) “a pesquisa é vista pelos órgãos direcionadores da educação nacional como elemento fundamental na formação de profissionais nas mais variadas áreas do saber”. Contudo, somente gerará avanços se for capaz de transformar um indivíduo socialmente, conforme afirma Fávero (2012, p. 15) ao citar que: "uma pesquisa apenas se justifica se for capaz de produzir processos educativos nos envolvidos [...] a pesquisa somente produzirá avanços se for capaz de realizar uma catarse nos envolvidos". Nesse sentido, esse autor afirma que a pesquisa deve se tornar um auxílio na busca do entendimento de problemas contribuindo para o processo do conhecimento (Fávero, 2012) e pode apresentar soluções acompanhadas de ações concretas, atuando como propulsora da promoção do campo profissional (Schmidt \& Sanches, 2011).

Destarte, para que ocorra a evolução de uma área é necessário o desenvolvimento de pesquisas científicas relevantes, reconhecidas pela sociedade e bem estruturadas (Bíscoli, 2012; Durante et al., 2016). Corroborando com tais afirmações, Nascimento (2012, p. 112) cita que "para que uma área seja reconhecida institucionalmente, no Brasil, é necessário que a 
investigação científica dessa área se desenvolva [...] com vasta produção acadêmicocientífica".

Todavia, a área de Secretariado não é reconhecida como área do conhecimento no CNPq, fato que, conforme Maçaneiro (2011, p. 9), é agravante, visto que gera "dificuldades acadêmicas, relacionadas com os fins de ensino, pesquisa e aplicação prática dos conhecimentos".

Ressalta-se também que a falta de programas de pós-graduação stricto sensu na área de Secretariado consiste em fator inibidor às produções científicas nesse campo, tendo em vista que os profissionais que desejam ingressar nesses programas devem fazê-lo em áreas afetas à sua formação (Durante, 2012). A inexistência desses programas, conforme Piccoli et al. (2016), traz prejuízos à área secretarial.

Ocorre que, ao ingressar em cursos de mestrado e doutorado, os profissionais de Secretariado Executivo voltam suas pesquisas às áreas e linhas de pesquisa do programa que estão cursando, direcionando, assim, um olhar para pesquisas que, por vezes, não se relacionam ao Secretariado (Durante, 2012; Bíscoli \& Bilert, 2013; Piccoli et al., 2016).

Ainda, Piccoli et al. (2016, p. 113) citam que:

[...] o fato de o Secretariado não ser reconhecido como uma área do conhecimento, possuir poucos grupos de pesquisa, docentes e coordenadores dos cursos superiores com pós-graduações stricto sensu em outras áreas forma um ciclo que agrava a situação do Secretariado no âmbito acadêmico e contribui para a inexistência de um curso stricto sensu na área [...].

Nesse cenário, Oliveira e Durante (2016, p. 75) alertam para o fato de que "a constituição de uma cultura voltada para a pesquisa no Secretariado depende do maior envolvimento de todos os atores [...]" abarcados no processo. Para além dessas colocações, Sanches, Schmidt e Dias (2017) afirmam que é fundamental o desenvolvimento de linhas de pesquisa que possam contribuir na elaboração de pesquisas voltadas especificamente para o Secretariado.

Assim, acredita-se que o desenvolvimento de investigações direcionadas à área, juntamente com a estruturação de linhas de pesquisa e com o envolvimento dos docentes e pesquisadores, possam levar ao surgimento de cursos de pós-graduação em nível stricto sensu na área e a consolidação da pesquisa em Secretariado. 


\subsection{A Pós-graduação stricto sensu no Brasil - relação entre produção científica e linhas de pesquisa}

A pós-graduação stricto sensu possui um papel preponderante no que tange ao desenvolvimento econômico, tecnológico e social do país, além de servir como base para formação de recursos humanos aptos a atuarem em diferentes setores da sociedade. Nos últimos anos, a pós-graduação stricto sensu tem passado por notável expansão tanto em relação à oferta de cursos, quanto em relação à abrangência no tocante às áreas do conhecimento (Bifano, 2009).

Formalmente instituída em meados dos anos de 1960, dez anos depois, o número de cursos na pós-graduação brasileira já caminhava para um milhar. Atualmente, existem, de acordo com a Capes (2017), 6.471 cursos de mestrado e doutorado em funcionamento no País. Destes, 2.205 doutorados e 4.266 mestrados. Em relação ao quantitativo de alunos formados, em 1996, por exemplo, 10.482 alunos obtiveram o título de mestre e 2.854 de doutor. Já em 2014, esse número passou para 50.206 mestres e 16.729 doutores, gerando um estoque de 445.562 profissionais com titulação de mestrado e de 177.053 de doutorado no país. Em termos comparativos, o Brasil ainda está distante de demais países do mundo em relação à taxa de indivíduos com doutorado (7,6 por cada 100 mil habitantes). Na Eslovênia, por exemplo, o país que mais detém doutores percentualmente ao total da população, possui 56,6 doutores por grupo de 100 mil habitantes (Daher, 2016).

Apesar disso, é fato que a pós-graduação no Brasil avançou muito nas últimas décadas, principalmente ao serem criadas oportunidades para doutoramento no país, possibilitando uma expressiva formação de pesquisadores e professores universitários que impulsionaram a geração de novos programas stricto sensu (Cruz, 2010). Entretanto, esse avanço e desenvolvimento não ocorreram de forma homogênea em todas as regiões do país, concentrando-se em grandes centros, a exemplo de Brasília, com 16,7 doutores para cada 100 mil habitantes no período compreendido entre 1996 a 2014; Rio Grande do Sul, com uma proporção média de 14,1; São Paulo, 13,9; e, Rio de Janeiro, 13,1. Por outro lado, em estados como Acre e Roraima, não há presença de doutores no período da pesquisa, e em estados como Piauí, Tocantins, Amapá, Maranhão e Rondônia, a proporção é inferior a um doutor para cada grupo de 100 mil habitantes (Daher, 2016).

R.G. Secr., GESEC, São Paulo, v. 9, n. 1, p 18-41, jan./abr. 2018. 
Essas disparidades em relação ao quantitativo de doutores por estados remetem a discussões sobre a necessidade de políticas de fomento visando à equidade da oferta de pósgraduação stricto sensu nas distintas unidades federativas, principalmente aquelas menos favorecidas com esse tipo de qualificação, muito embora, atualmente, todos os estados do país contam com programas stricto sensu, ainda que de maneira desproporcional. Cirani, Campanario e Silva (2015), em análise sobre as divergências regionais em relação ao desenvolvimento e expansão das pós-graduações no Brasil, afirmam que o país ainda necessita de uma política mais descentralizada quanto a esse tipo de qualificação profissional, possibilitando que indivíduos de regiões menos desenvolvidas também tenham acesso à pósgraduação stricto sensu.

Para além das disparidades regionais da oferta de pós-graduação, outro aspecto que merece atenção diz respeito ao crescimento diferenciado das diversas grandes áreas do conhecimento. Ao longo da história da pós-graduação stricto sensu no país, as áreas de Humanas, Saúde e Agrárias, entre outras, congregavam a maior parte da oferta de cursos. Hoje, a área multidisciplinar é responsável pela oferta de 445 cursos stricto sensu, distanciando-se da segunda maior área, a de Ciências Agrária, que oferta 370 cursos (Capes, 2017).

Essa mudança de cenário vem ao encontro com o proposto no Plano Nacional de PósGraduação (PNPG), decênio 2011-2020, que sugere a criação de programas centrados em torno de novas formações, atendendo a demanda por formação em áreas não contempladas nos programas existentes. Isso porque, embora a oferta de cursos stricto sensu seja superior a 6.000, ainda existem formações de ensino superior que não dispõem de programas stricto sensu, a exemplo do Secretariado Executivo, que, apesar de formar bacharéis há, praticamente, meio século, ainda não verticalizou suas atividades.

Entretanto, a criação de programas de pós-graduação stricto sensu demanda, além de políticas educacionais, a estruturação das próprias áreas do conhecimento. De acordo com Borges e Casado (2009), anterior à proposição de curso de stricto sensu, faz-se necessário que as instituições elaborem uma agenda de pesquisa que priorize problemas considerados prioritários e relevantes para a comunidade científica, estabelecendo claramente as linhas de pesquisa para a área.

Menandro (2003) corrobora Borges e Casado (2009) ao afirmar que: 
Linhas de pesquisa são um conceito largamente utilizado em curriculum vitae, em descrição de grupos de pesquisas, na especificação da abrangência de Programas de Pós-graduação, em documentos oficiais de agências de fomento, destacado como elemento importante a ser considerado no âmbito da avaliação dos Programas de Pós-graduação e que precisa ser considerado pelos formuladores de novas propostas de novos cursos de pós-graduação (Menandro, 2003, p. 01).

A Capes, fundação pública criada para subsidiar o Ministério da Educação na formulação de políticas públicas para a pós-graduação, bem como para coordenar e avaliar os cursos deste nível, considera as linhas de pesquisa como um dos fatores de impacto para a avaliação dos programas (Capes, 2017). No caso dos programas stricto sensu em Administração Pública e de Empresas, Ciências Contábeis e Turismo, por exemplo, a Capes estabelece que "as linhas de pesquisa precisam expressar a especificidade de produção de conhecimento da respectiva área de concentração, representando um recorte específico e bem delimitado da área de concentração" (Capes, 2016, p. 09). Para a área supracitada, as linhas de pesquisa fazem parte do rol de itens de maior peso nas avaliações dos programas, considerando como item de avaliação, entre outros aspectos, se os projetos desenvolvidos pelos docentes integrantes do corpo docente do curso apresentam coerência com as linhas de pesquisa, bem como com a distribuição dos projetos pelas distintas linhas de pesquisa dos programas.

Além disso, autores como Menandro (2003) e Borges e Casado (2009) chamam a atenção também para a atuação dos pesquisadores em linhas distintas de pesquisa. Para eles, a atuação em temáticas diferentes pode prejudicar os processos de análises para a abertura e avaliação de programas já existentes, além de dificultar o desempenho do pesquisador que, se dedicando apenas a uma temática, poderá publicar em maior quantidade e, por consequência, maior qualidade. "Quando o pesquisador permanece na pesquisa da mesma questão por longo tempo, sua produção é mais consistente" (Borges \& Casado, 2009, p. 131).

Especificamente no caso do Secretariado Executivo, a investigação científica tem sido objeto de estudos recentes publicados principalmente em anais de eventos científicos da área, a exemplo do Encontro Nacional de Estudantes de Secretariado Executivo - Enesec, Encontro Nacional Acadêmico de Secretariado Executivo - Enasec, e revistas indexadas especializadas na área. Tais estudos, contudo, só apareceram com mais nitidez na literatura da área, a partir do final da primeira década dos anos de 2000, ganhando maior visibilidade nos últimos anos com a criação de uma associação nacional de pesquisadores, surgimento e fortalecimento de 
grupos de pesquisa e publicações de livros e artigos com reflexões sobre a construção do conhecimento em secretariado (Sanches et al., 2016).

Todavia, esses avanços na área, embora incipientes, estão em consonância com o que preconiza Carneiro e Lourenço (2003) sobre as vantagens da pesquisa científica. Para eles, a pesquisa científica é o melhor caminho para conduzir uma área científica rumo à pósgraduação stricto sensu.

\section{Metodologia}

Esta pesquisa é caracterizada como um estudo estatístico-descritivo, de abordagens qualitativa e quantitativa, que discorre sobre a compatibilidade existente entre as produções científicas dos membros pesquisadores e as linhas de pesquisa do GPSEB, no quadriênio (2013-2016). Assim, o cunho estatístico-descritivo, combinando as abordagens qualitativa e quantitativa, é justificado por utilizar técnicas estatísticas para estudar aspectos específicos da produção científica dos integrantes do GPSEB, de maneira a descrever a relação existente entre os trabalhos realizados pelos membros pesquisadores e as linhas de pesquisa do referido grupo.

No que tange à população do estudo, esta é composta especificamente por todos os membros incluídos na categoria de pesquisadores do GPSEB, totalizando 20 integrantes. Assim, não foram incluídos na análise os estudantes, os técnicos e os colaboradores estrangeiros. Justifica-se essa escolha pelo fato de que os pesquisadores são os principais contribuintes com a docência em Secretariado Executivo e, consequentemente, com o possível desenvolvimento de cursos stricto sensu na área. Isso não significa que as pesquisas realizadas pelos demais membros são menos importantes ou menos significativas para a construção de conhecimento na área secretarial, apenas que, para o recorte deste artigo, cujo olhar é em direção ao stricto sensu, os pesquisadores apresentam relação mais direta, por sua maior relação com a docência.

Em relação à coleta de dados, essa foi realizada seguindo dois passos, ambos tendo como base os currículos dos membros pesquisadores do GPSEB, certificados na Plataforma 
Lattes - Diretório dos Grupos de Pesquisa - CNPq. É importante ressaltar que todos os currículos Lattes foram observados no período de 23 a 27 de junho de 2017, de forma que não foi possível ser considerar qualquer atualização feita posteriormente.

No primeiro momento da coleta de dados buscou-se verificar e quantificar os seguintes indicadores de cada um dos 20 pesquisadores (todos observados no quadriênio 2013-2016):

a) área da graduação;

b)última titulação;

c) projetos de pesquisa;

d)artigos completos publicados em periódicos;

e) livros publicados;

f) capítulos de livros publicados;

g)trabalhos completos publicados em anais de congressos;

h)resumos expandidos publicados em anais de congressos;

i) resumos publicados em anais de congressos.

Cabe apontar que, para este estudo, o quantitativo e a análise das categorias "resumos expandidos publicados em anais de congressos" e "resumos publicados em anais de congressos" foram realizados conjuntamente, de maneira que o indicador foi nomeado apenas como "resumos publicados em anais de congressos". Dessa forma, foi analisado um total de oito aspectos. A justificativa para a determinação dessas categorias de análise é que essas produções são as que mais pontuam na Capes quando se refere à análise e avaliação de projetos para a criação de novos cursos stricto sensu.

Num segundo momento, verificou-se a compatibilidade existente entre as produções científicas dos pesquisadores e as linhas de pesquisa existentes no grupo. Nesse sentido, conforme já exposto, as linhas de pesquisa do GPSEB são: Assessoria e Gestão Organizacional; Empreendedorismo, Inovação e Internacionalização; Gestão Socioambiental nas Organizações e Língua Estrangeira Moderna (CNPq, 2017). Cientes dessas linhas de pesquisa, e com posse do quantitativo resultante das oito categorias de análise, foram buscadas informações para relacionar a produção científica com as linhas de pesquisa.

Para tanto, foram lidos os títulos de todas as produções (conforme as categorias apontadas) de cada um dos 20 pesquisadores, procurando identificar: a) se havia relação do estudo com alguma das linhas de pesquisa do GPSEB; b) se o Secretariado/área secretarial, em específico, era foco do estudo. Para indicar se o trabalho era compatível ou não com 
alguma linha de pesquisa do GPSEB, utilizou-se a análise de conteúdo. Já para indicar se a pesquisa tinha como foco o Secretariado, observou-se a presença de palavras específicas que remetessem a essa área, tais como: secretariado, secretariado executivo, secretarial, secretário (a), secretariais.

Com posse dos dados coletados, as discussões e análises foram realizadas de forma estatística-descritiva, com o auxílio do software Excel para a geração de gráficos e quadros que facilitassem a compreensão.

\section{Análise e Discussão dos Resultados}

Inicialmente, apresentam-se dados relativos à área de formação, ao grau de titulação e à quantidade de publicações (por categoria de análise) dos membros pesquisadores do GPSEB. Assim, do total de 20 pesquisadores, 14 possuem graduação em Secretariado Executivo, cinco em Letras e um deles em Administração. Já no que se refere à última titulação deles, tem-se um pós-doutor, oito doutores, sete mestres, um especialista e três graduados.

Nesse sentido, observa-se compatibilidade entre a formação dos pesquisadores com as linhas de pesquisa do grupo, pois as três áreas de formação estão em consonância com as linhas de formação do Secretariado Executivo no Brasil, conforme consta nas DCN do curso (Brasil, 2005), e, num segundo momento, em consonância também com os objetivos do grupo de pesquisa em análise. Cabe destacar que, embora haja presença de pesquisadores nas três linhas, a maior quantidade de pesquisadores com formação em Secretariado é um aspecto positivo dada a especificidade do grupo, que busca desenvolver pesquisas em Secretariado, a fim de contribuir com o desenvolvimento da área. Outro aspecto que também contribui com o quantitativo e a qualidade das pesquisas desenvolvidas pelo GPSEB é a titulação dos pesquisadores, composta por $45 \%$ de doutores e pós-doutores, além de $35 \%$ de pesquisadores com título de mestrado.

Em relação ao quantitativo de produções dos membros pesquisadores, é importante ressaltar que todos os trabalhos científicos foram analisados individualmente, de forma que as pesquisas realizadas em conjunto podem pontuar para mais de um pesquisador, sendo incluído no total de publicações. Para tanto, a quantidade de trabalhos científicos dos integrantes pesquisadores do GPSEB, no quadriênio 2013-2016, é apresentada no Gráfico 1.

R.G. Secr., GESEC, São Paulo, v. 9, n. 1, p 18-41, jan./abr. 2018. 


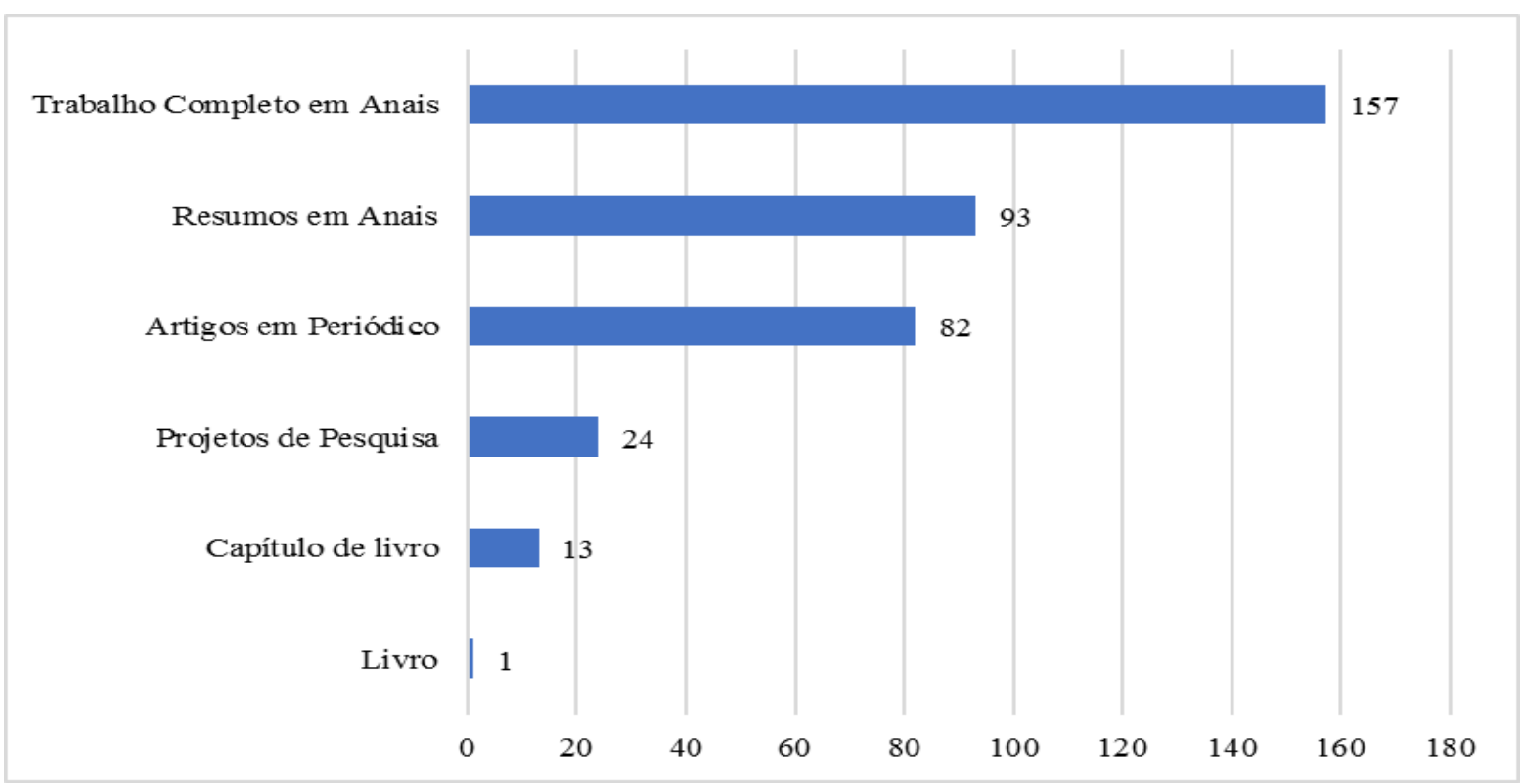

Gráfico 1 - Produção científica dos pesquisadores do GPSEB no quadriênio 2013-2016 Fonte: dados da pesquisa (2017).

Uma primeira análise permite inferir que o grupo produziu, ao longo do quadriênio, 370 trabalhos, sendo predominantes $(67 \%)$ as produções em trabalhos completos e resumos publicados em anais de eventos. Tal resultado pode ser atrelado ao fato de eventos científicos serem veículos com maior facilidade e celeridade de publicação se comparados a outros, como, por exemplo, periódicos, capítulos e livros. Vale destacar, ainda, que essas publicações demonstram a efetiva participação dos membros do GPSEB em eventos científicos, contribuindo, dessa forma, com o avanço da área secretarial e também de áreas afins.

Por outro lado, dada a importância que a Capes atribui às publicações em periódicos, cabe um olhar dos pesquisadores para esta forma de divulgação das pesquisas, uma vez que, no período em análise, estas representaram somente $22 \%$ do total de publicações. Nesse sentido, seria importante que os pesquisadores, após as apresentações em eventos científicos, aprimorassem seus estudos e os submetessem também para periódicos.

Ademais, outra reflexão possível diz respeito à publicação de livros. Considerando que o GPSEB atua desde o ano de 2002 e, atualmente, congrega pesquisadores com elevada qualificação, seria desejável a sistematização das linhas de estudo do grupo, a partir de publicação de livros, aspecto ainda pouco explorado pelo grupo.

$\mathrm{Na}$ sequência, visando atingir o propósito central deste estudo, desenvolveram-se análises relativas à compatibilidade das produções científicas dos pesquisadores com as linhas de pesquisa do GPSEB. Especificamente, neste momento, cada uma das 370 publicações foi 
analisada com o intuito de investigar se estão ajustadas com uma ou mais linhas de pesquisa do grupo, pois os dados demonstraram que um mesmo trabalho, independentemente da forma de publicação, pode estar ligado a mais de uma das linhas de pesquisa.

Ademais, lembra-se que, neste primeiro momento, não se observou se os trabalhos tinham ou não relação específica com o Secretariado Executivo, apenas se o estudo era compatível com alguma das linhas de pesquisa do grupo. Assim, a distribuição das publicações por linha de pesquisa pode ser observada no Gráfico 2. Vale ressaltar que as publicações sem relação com as linhas investigadas não foram computadas neste gráfico.

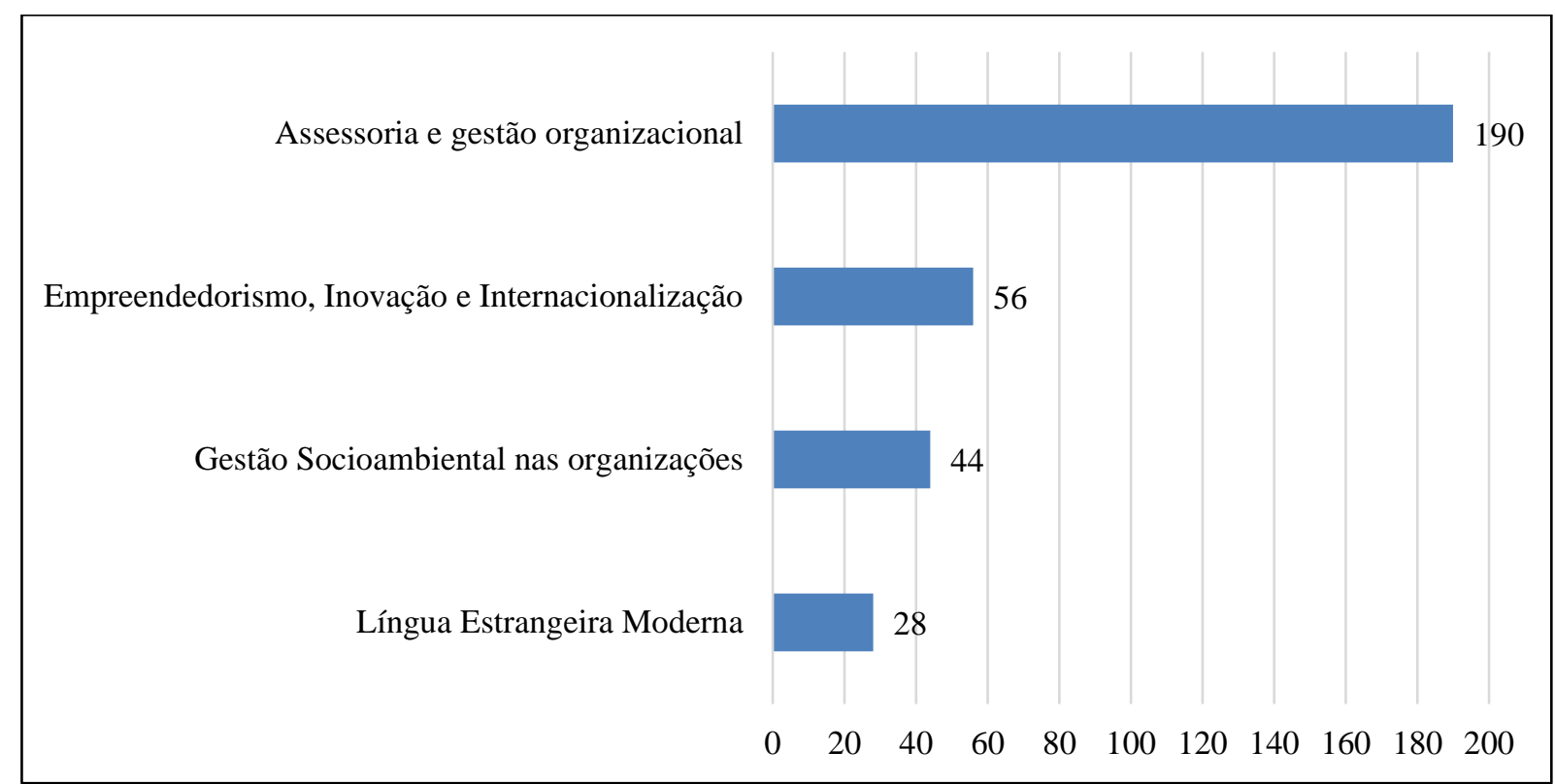

Gráfico 2 - Quantitativo da produção científica relacionada com as linhas de pesquisa. Fonte: dados da pesquisa (2017).

Primeiramente, observou-se um resultado que pode ser considerado positivo no que tange ao quantitativo de publicações que apresentaram compatibilidade com as linhas de pesquisa, uma vez que 318 vezes foram encontradas relações entre os estudos e as linhas de pesquisa do grupo.

Além disso, no período em análise, foram encontradas produções científicas nas quatro linhas do grupo de pesquisa. Esse resultado é um fator importante, dada a intenção dos referidos pesquisadores sobre a proposição de um programa stricto sensu para a área, uma vez que, para a Capes (2016), as linhas de pesquisa fazem parte do rol de itens de maior peso nas avaliações dos programas.

R.G. Secr., GESEC, São Paulo, v. 9, n. 1, p 18-41, jan./abr. 2018. 
Cabe destacar que dentre as linhas, a de maior destaque é a de Assessoria e Gestão Organizacional, na qual foram computadas 190 publicações. Isso pode ser reflexo da formação dos pesquisadores, que em sua maioria são graduados na área de Secretariado. Mediante tal resultado, a concepção de uma proposta stricto sensu possui maior compatibilidade com a área de Assessoria e Gestão Organizacional.

Outra linha de pesquisa que também pode ser contemplada numa proposta stricto sensu é a de Empreendedorismo, Inovação e Internacionalização, dado o quantitativo de publicações e a proximidade destas temáticas com a essência da formação em Secretariado.

Além de verificar a existência de trabalhos que possuem relação com as linhas de pesquisa, observaram-se também quais foram os meios de publicação desses estudos, conforme demonstrado no Quadro 1.

Quadro 1 - Produção científica relacionada às linhas de pesquisa e subdividida por categoria.

\begin{tabular}{|l|l|l|l|l|l|l|}
\hline Linhas de pesquisa & $\begin{array}{l}\text { Projetos } \\
\text { Pesquisa }\end{array}$ & $\begin{array}{l}\text { Artigos em } \\
\text { Periódico }\end{array}$ & Livro & $\begin{array}{l}\text { Capítulo } \\
\text { de livro }\end{array}$ & $\begin{array}{l}\text { Trabalho Completo } \\
\text { em Anais }\end{array}$ & $\begin{array}{l}\text { Resumos } \\
\text { em Anais }\end{array}$ \\
\hline $\begin{array}{l}\text { Assessoria e Gestão } \\
\text { Organizacional }\end{array}$ & 14 & 39 & 1 & 3 & 96 & 37 \\
$\begin{array}{l}\text { Empreendedorismo, } \\
\text { Inovação } \\
\text { Internacionalização }\end{array}$ & 2 & 15 & 0 & 3 & 24 & 12 \\
\hline $\begin{array}{l}\text { Gestão Socioambiental nas } \\
\text { organizações }\end{array}$ & 9 & 11 & 0 & 1 & 17 & 6 \\
\hline $\begin{array}{l}\text { Língua } \\
\text { Moderna Estrangeira }\end{array}$ & 1 & 5 & 0 & 1 & 10 & 11 \\
\hline Total & $\mathbf{2 6}$ & $\mathbf{7 0}$ & $\mathbf{1}$ & $\mathbf{8}$ & $\mathbf{1 4 7}$ & $\mathbf{6 6}$ \\
\hline
\end{tabular}

Fonte: dados da pesquisa (2017).

Em relação às duas possíveis linhas de pesquisa para a proposta stricto sensu (Assessoria e Gestão Organizacional e Empreendedorismo, Inovação e Internacionalização), faz-se necessário uma maior convergência de esforços dos pesquisadores no sentido de alinharem suas produções para publicações em periódicos e livros. Até o momento, as produções concentram-se em anais de eventos. Trata-se de um aspecto importante a ser observado e alterado ao longo do tempo.

Além disso, cabe destacar o quantitativo de projetos de pesquisa compatíveis com as duas linhas de pesquisa em discussão, fator este positivo para o stricto sensu, haja vista que 
projetos de pesquisa também são elementos avaliados e computados pela Capes (2016), quando da proposição de novos programas no país.

Na sequência, os dados coletados permitiram analisar se, para além da compatibilidade com as linhas de pesquisa, os estudos possuem relação com a essência do grupo de pesquisa, qual seja: discussões sobre temáticas relativas ao Secretariado Executivo. Nesse sentido, do total das publicações analisadas, apenas 14\% delas não apresentaram compatibilidade nem com as linhas de pesquisa, tampouco com a área secretarial, aspecto considerado positivo para o grupo, numa primeira análise.

Num segundo momento, analisou-se a compatibilidade das produções especificamente para com o Secretariado Executivo. Para tanto, foi observado se nos títulos das produções havia palavras específicas da área secretarial, de acordo com o exposto nos procedimentos metodológicos. Os resultados podem ser visualizados no Gráfico 3.

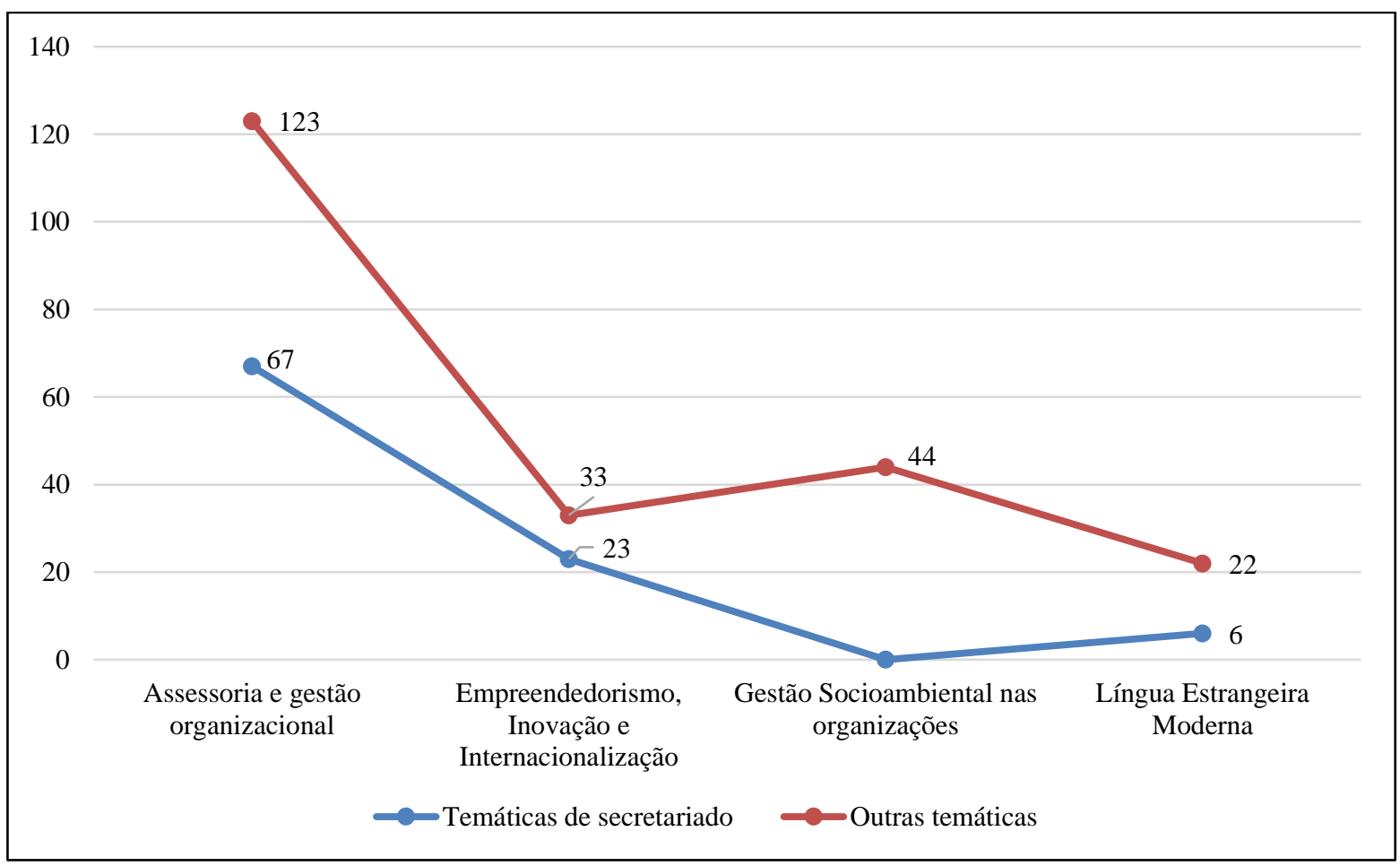

Gráfico 3 - Estudos relacionados às linhas de pesquisa do GPSEB e ao Secretariado Executivo. Fonte: dados da pesquisa (2017).

Considerando a intenção de um programa stricto sensu no Secretariado Executivo, os resultados demonstram a necessidade de realinhamento das publicações, uma vez que apenas $30 \%$ delas versam diretamente sobre a área. Essa necessidade de reestruturação se aplica para 
todas as linhas do GPSEB, especialmente para aquelas com maior potencial de proposição do programa.

O cenário apresentado no Gráfico 3 pode ser reflexo da inexistência de programas stricto sensu na área no país (Durante, 2016), o que demanda dos pesquisadores uma qualificação em mestrados e doutorados distintos de sua área de formação de graduação (Piccoli et al., 2016), nos quais eles sentem a necessidade de publicar. Outros ainda atuam enquanto docentes em programas stricto sensu vinculados a outras áreas, e, portanto, desenvolvem suas pesquisas nesses universos. Contudo, para Menandro (2003) e Borges e Casado (2009), a atuação de pesquisadores em linhas distintas de pesquisa não é positivo para os processos de abertura e avaliação de programas, além de dificultar o desempenho do pesquisador que, se dedicando apenas a uma temática, poderá publicar em maior quantidade e, por consequência, maior qualidade.

Dessa forma, por um lado, percebe-se a necessidade do realinhamento das pesquisas, mas, por outro, sabe-se também das dificuldades enfrentadas pelos pesquisadores em questão, dada a diversidade das suas qualificações stricto sensu. Assim, acredita-se que o realinhamento será possível, porém não em um curto espaço de tempo. Inclusive, a possibilidade da abertura de um programa stricto sensu será fator chave para que um maior ajustamento das publicações ocorra no futuro.

Por fim, os dados coletados permitiram uma última análise para o presente estudo. Identificaram-se alguns trabalhos com foco de estudo no Secretariado Executivo, mas sem relação com nenhuma das quatro linhas de pesquisa existentes atualmente no GPSEB. Nesses casos, buscou-se saber quais temáticas e possíveis linhas novas de pesquisa estavam sendo abordadas. O Gráfico 4 apresenta esses resultados.

Conforme pode ser visualizado, um significativo número de publicações (77) conduz ao entendimento sobre a possibilidade ou, até mesmo, sobre a necessidade da construção de duas novas linhas de investigação no grupo, quais sejam: Pesquisa em Secretariado Executivo; e, Formação em Secretariado Executivo. Ambas as temáticas voltam seu olhar para a essência da formação do profissional de Secretariado e para a construção epistemológica da área. 


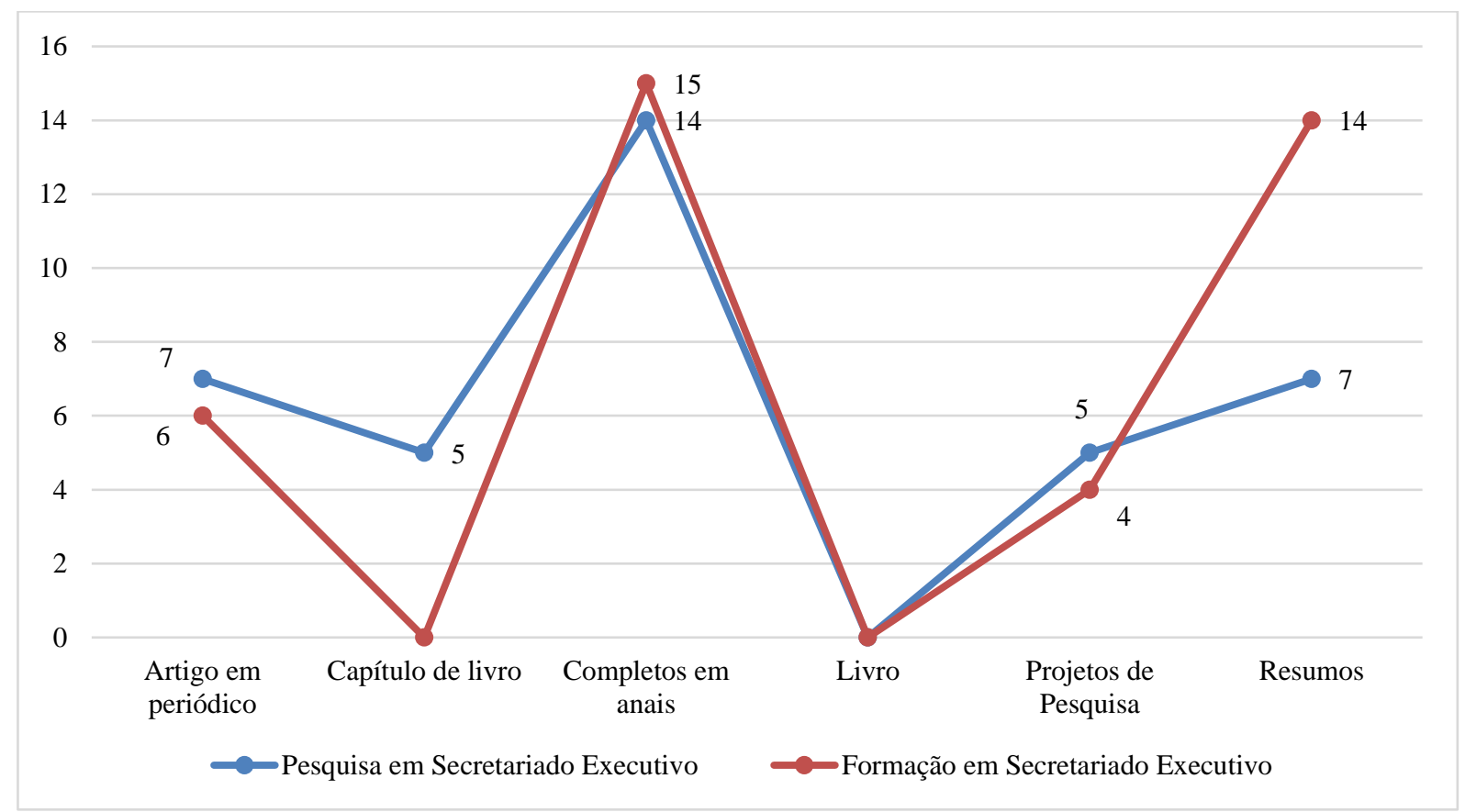

Gráfico 4 - Pesquisas voltadas ao secretariado e não contempladas nas linhas de pesquisa do GPSEB. Fonte: dados da pesquisa (2017).

Acredita-se que esse resultado seja reflexo da preocupação desses pesquisadores, que, em consonância com os demais pesquisadores da área do Secretariado Executivo no Brasil, desde meados de 2010, se preocupam de forma nítida e massivamente com a consolidação da profissão, a partir da pesquisa. Desse modo, os pesquisadores do GPSEB, preocupados em contribuir com o cenário nacional da área, também estão voltando esforços para esses temas.

Nesse sentido, tem-se então uma lacuna a ser discutida e repensada no grupo em questão, demonstrando a necessidade de outro possível realinhamento. Pode-se considerar que as duas temáticas aqui apresentadas têm sido foco de investigação no grupo, uma vez que apresentam mais publicações (Gráfico 3) do que as outras três linhas de pesquisa (Empreendedorismo, Inovação e Internacionalização; Gestão Socioambiental nas organizações; Língua Estrangeira Moderna) atualmente existentes no grupo.

De modo geral, ao longo deste estudo foram apresentadas algumas considerações acerca de temáticas e linhas de pesquisa existentes no GPSEB, tema este que se torna relevante na atual conjuntura, dado: o interesse do grupo na proposição de um programa stricto sensu; a importância da compatibilidade das linhas e temáticas com as produções científicas dos pesquisadores em função de tal critério exigido pela Capes; e, por fim, o consenso da comunidade científica do Secretariado no Brasil sobre a necessidade e urgência da abertura de programas de mestrado na área.

R.G. Secr., GESEC, São Paulo, v. 9, n. 1, p 18-41, jan./abr. 2018. 


\section{Considerações Finais}

O estudo aqui apresentado lança um olhar para a produção científica da área secretarial rumo à formação stricto sensu. Sabe-se que as colocações aqui inferidas são baseadas no caso do GPSEB, mas entende-se também que podem conduzir importantes reflexões para outros pesquisadores, grupos, centros e universidades. Isto é, considerando que, neste momento, a área de Secretariado no Brasil se preocupa com a formação em nível de mestrado e doutorado, discussões acerca de produções científicas, linhas de pesquisa e a compatibilidade entre elas se mostram relevantes em âmbito nacional. Dessa forma, a temática merece ser discutida, podendo ser este estudo o início de um debate maior.

O título desta pesquisa remete a reflexão de que, para alcançar a esperada formação stricto sensu, algumas mudanças e adequações podem ser necessárias. No caso do GPSEB, entende-se que os pesquisadores apresentam possibilidades concretas para ofertar um programa de mestrado, uma vez que possuem uma longa trajetória de estudos no referido grupo, apresentam um corpo docente qualificado para tal, bem como desenvolveram um número significativo de pesquisas e publicações no último quadriênio. Contudo, o Mutatis Mutandis conduziu a reflexões específicas, indicando aspectos importantes para serem discutidos e talvez alterados. Dentre eles, especial atenção deve ser dada a uma maior quantidade de publicações voltadas especificamente para o Secretariado Executivo, a exemplo de estudos empíricos que englobem o profissional Secretário Executivo como foco de estudo.

Também, são necessárias mais produções em periódicos e livros, além da necessidade de repensar sobre a manutenção de algumas linhas de pesquisa que possuem reduzidas produções no grupo, por exemplo, a de Língua Estrangeira Moderna. Ainda, o repensar do GPSEB sobre a possibilidade de junção de linhas que possuem um objeto de estudo semelhante, tais como: a de Gestão Socioambiental nas organizações e a de Assessoria e Gestão Organizacional.

Somado a isso, destaca-se que os pesquisadores vêm produzindo estudos voltados para a pesquisa e a formação em Secretariado Executivo, temáticas essas não contempladas enquanto linhas de pesquisa do grupo. Tais ajustes são fundamentais, dada a importância que a Capes estabelece para a questão da compatibilidade existente entre as produções científicas e as linhas de pesquisa. 
Há que se considerar ainda que este estudo não teve o propósito de fornecer considerações precisas e finais para tais reflexões, mas, sim, de lançar um olhar sobre um aspecto importante para o grupo de pesquisa em questão, e que parece ser de interesse da comunidade científica secretarial como um todo.

Assim, acredita-se que as questões aqui abordadas possam subsidiar a composição de uma agenda de pesquisas futuras, talvez mais concretas, com vistas ao acompanhamento da produção científica do GPSEB e de demais grupos de pesquisa da área de Secretariado no Brasil, que anseiam pela abertura da formação stricto sensu.

Diante disso, sugere-se, por exemplo, um olhar para a evolução das publicações do grupo em estudo, buscando identificar se a produção específica na área de secretariado tem aumentado ou diminuído ao longo do tempo. Ademais, fica a sugestão de uma análise que contemple não apenas os títulos dos estudos, mas também o trabalho como um todo, favorecendo análises de expressões-chave, nuvens de palavras e outras relações possíveis entre publicações e linhas de pesquisa.

\section{Referências}

Andrade, A. \& Soares, S. (2016). Docência na educação superior: área de atuação para o profissional de Secretariado Executivo. In Barros, C; Silva, J. \& Dias, A. (orgs.). Secretariado executivo e educação: temas que se articulam pela formação, docência na educação superior e pesquisa científica. Fortaleza: Edições UFC.

Bifano, M. R. (2009). Normalização de trabalhos acadêmicos: considerações sobre o impacto ambiental e o consumo responsável. Dissertação de Mestrado. Programa de Pósgraduação em Metrologia da PUC-Rio.

Bíscoli, F. R. V. (2012). A evolução do Secretariado Executivo: caminhos prováveis a partir dos avanços da pesquisa científica e dos embates teóricos e conceituais na área. In Durante, D. G (Org.). Pesquisa em secretariado: cenários, perspectivas e desafios. Passo Fundo: Ed. Universidade de Passo Fundo. 
Bíscoli, F. R. V. \& Bilert, V. S. S. (2013). A evolução do Secretariado Executivo: caminhos prováveis a partir dos avanços da pesquisa científica e dos embates teóricos e conceituais na área. Revista Expectativa. Toledo: Unioeste, vol. 12, n.12.

Borges, M. M., \& Casado, E. S. (2009). A ciência da informação criadora do conhecimento. Coimbra: IDIBCIC.

Brasil. (2005). Resolução n. 3, de 23 de junho de 2005 - Institui as Diretrizes Curriculares Nacionais para o curso de graduação em Secretariado Executivo e dá outras providências. Ministério da Educação, Brasília.

Brito, D. \& Barros, C. (2016). Avaliação da aprendizagem na educação superior: quais as concepções de docentes de secretariado executivo? In Barros, C; Silva, J., \& Dias, A. (orgs.). Secretariado executivo e educação: temas que se articulam pela formação, docência na Educação Superior e pesquisa científica. Fortaleza: Edições UFC.

Cantarotti, A. (2016). Formação, mercado de trabalho e pesquisa científica: por onde começamos? In Durante, D. G.; Martins, C., \& Cantarotti, A. (orgs.). Pesquisa em Secretariado: reflexões acerca da construção o conhecimento. Fortaleza: Edições UFC.

Capes. (2017). Cursos recomendados e reconhecidos. Recuperado em 25 junho, 2017, de <sucupira.Capes.gov.br>.

- (2016). Requisitos para a apresentação de propostas de cursos novos (APCN): Administração, Ciências Contábeis e Turismo. MEC.

Carneiro Jr., S., \& Lourenço, R. (2003). Pós-graduação e pesquisa na universidade. In Viotti, E. B; \& Macedo, M. M. Indicadores de ciência, tecnologia e inovação no Brasil. Campinas: Unicamp, pp. 41-88.

Cirani, C. B. S; Campanario, M. De A., \& Silva, H. H. M. (2015 março). A evolução do ensino da pós-graduação senso estrito no Brasil: análise exploratória e proposições para pesquisa. Avaliação, Campinas; Sorocaba, SP, vol. 20, n. 1, pp. 163-187, mar.

CNPQ. (2017). Diretórios dos grupos de pesquisa. Recuperado em 10 maio, 2017, de <http://lattes.cnpq.br/web/dgp>.

R.G. Secr., GESEC, São Paulo, v. 9, n. 1, p 18-41, jan./abr. 2018. 
Cruz, C. H. de B. (2010 jun.). Ciência, tecnologia e inovação no Brasil: desafios para o período 2011 a 2015 (4a. ed.). Interesse Nacional.

Daher, S. (2016). Mestres e doutores 2015: estudos da demografia da base técnico-científica brasileira. Brasília, DF: CGEE.

Durante, D. G. (2012). A evolução da profissão secretarial por meio da pesquisa. In Durante, D. G (Org.). Pesquisa em secretariado: cenários, perspectivas e desafios. Passo Fundo: Ed. Universidade de Passo Fundo.

Durante, D. G.; Gonçalves, O. B.; Nascimento, D. E. L. \& Pontes, E. S. (2016). Produção científica em secretariado: Percepções a partir das publicações da Revista Expectativa. In Durante, D. G; Martins, C., \& Cantarotti, A. (Orgs.). Pesquisa em Secretariado: reflexões acerca da construção o conhecimento. Fortaleza: Edições UFC.

Fávero, A. B. (2012). "Decifra-me ou te devoro": pesquisa na sociedade do conhecimento. In Durante, D. G (Org.). Pesquisa em secretariado: cenários, perspectivas e desafios. Passo Fundo: Ed. Universidade de Passo Fundo.

Maçaneiro, M. B. (2011). Antecedentes, consequências e desafios da cientificidade da área de Secretariado Executivo. Revista Expectativa. vol. 10, n. 10.

Martins, C. \& Zanon, M. (2013). A pesquisa na área do Secretariado. Em D’Elia, B.; Amorim, M. \& Sita, M. (Orgs.). Excelência no Secretariado: A importância da profissão nos processos decisórios. Como assessorar e atingir resultados corporativos e pessoais com competência e qualidade. São Paulo: Ser Mais.

Menandro, P. R. M. (2003, abr./jun.). Linha de pesquisa: possibilidades de definição e tipos de utilização do conceito. $R A C, 7(2)$, abr./jun., 177-182.

Müller, R. \& Sanches, F. C. (2013). Pesquisa acadêmica em Secretariado Executivo: um estudo de caso na Revista Expectativa. Revista Expectativa, 13(13).

Nascimento, E. P. (2012). Pesquisa aplicada e interdisciplinaridade: da linguística ao secretariado. In Durante, D. G (Org.). Pesquisa em Secretariado: cenários, perspectivas e desafios. Passo Fundo: Ed. Universidade de Passo Fundo. 
Neiva, E. G.; D’Elia, M. E. (2014). As novas competências do profissional de Secretariado (3a ed.). São Paulo: IOB.

Oliveira, N. \& Durante, D. (2016). Os cursos de Secretariado Executivo incentivam a pesquisa? In Durante, D. G; Martins, C., \& Cantarorri, A. (Orgs.). Pesquisa em Secretariado: reflexões acerca da construção o conhecimento. Fortaleza: Edições UFC.

Piccoli, Á. L.; Gonçalves, J. F. T.; Soares, S. V., \& Martins; C. B. (2016). Secretariado Executivo e a pesquisa acadêmica: uma análise sobre a necessidade da criação de curso stricto sensu. In Durante, D. G; Martins, C. B., \& Cantarotti, A. (Orgs.). Pesquisa em Secretariado: reflexões acerca da construção o conhecimento. Fortaleza: Edições UFC.

Pontes, E. \& Durante, D. (2016). Estado do conhecimento em secretariado executivo: um estudo bibliométrico na Revista de Gestão e Secretariado (GeSec). In Barros, C; Silva, J., \& Dias, A. (Orgs.). Secretariado executivo e educação: temas que se articulam pela formação, docência na Educação Superior e pesquisa científica. Fortaleza: Edições UFC.

Sanches, F. C.; Schmidt, C. M.; Cielo, I. D., \& Wenningkamp, K. R. (2016). Grupos de pesquisa em Secretariado Executivo: uma análise sobre a cooperação científica internacional. In Durante, D. G; Martins, C. B. \& Cantarotti, A. (Orgs.). Pesquisa em Secretariado: reflexões acerca da construção o conhecimento. Fortaleza: Edições UFC.

Sanches, F. C.; Schmidt, C. M,. \& Dias, A. H. (2017). Os avanços da pesquisa em Secretariado Executivo: uma análise nos periódicos científicos nacionais. In Souza, C. K., \& Pereira, E. O conhecimento científico em Secretariado: reflexões sobre a produção acadêmica da área secretarial. João Pessoa: Ideia.

Schmidt, C. M.; Cielo, I. D., \& Sanches, F. C. (2012). Mapeamento de redes: um estudo sobre as relações entre universidades e docentes em cursos de Secretariado Executivo. In Durante, D. G. (Org.). Pesquisa em Secretariado Executivo: cenários, perspectivas e desafios (1a ed.). Passo Fundo: Ed. Universidade de Passo Fundo.

Schmidt, C. M., \& Sanches, F. C. (2011). Editorial. Revista Expectativa. Toledo, 10(10), 7-8. 